\title{
Влияние ионов неодима (III) на фотолюминесценцию сульфидов кадмия и цинка в полиакрилатной матрице
}

\author{
(C) В.П. Смагин, А.А. Исаева, Е.А. Шелепова
}

Алтайский государственный университет, 656049 Барнаул, Россия

E-mail: smaginV@yandex.ru

Поступила в Редакцию 11 октября 2021 г.

В окончательной редакции 18 октября 2021 г.

Принята к публикации 18 октября 2021 г.

Наноразмерные частицы $\mathrm{CdS}: \mathrm{Nd}^{3+}, \mathrm{ZnS}: \mathrm{Nd}^{3+}$ и $(\mathrm{Cd}, \mathrm{Zn}) \mathrm{S}: \mathrm{Nd}^{3+}$ синтезированы и легированы в среде полимеризующегося метилметакрилата в процессе получения оптически прозрачных полиакрилатных композитов состава ПММА/CdS: $\mathrm{Nd}^{3+}$, ПММА/ZnS: $\mathrm{Nd}^{3+}$ и ПММА/(Cd, Zn)S: $\mathrm{Nd}^{3+}$. Возбуждение фотолюминесценции и фотолюминесценция полупроводниковых структур в полиакрилатной матрице связаны с переходом электронов из валентной зоны в зону проводимости и на уровни структурных дефектов частиц с последующей рекомбинацией на этих уровнях. Исходя из изменений в спектрах возбуждения фотолюминесценции и фотолюминесценции композитов, высказаны предположения о структуре частиц, распределении в ней ионов $\mathrm{Nd}^{3+}$ и их влиянии на фотолюминесценцию.

Ключевые слова: коллоидный синтез, сульфид кадмия, сульфид цинка, легирование, неодим, полиметилметакрилат, композиты, фотолюминесценция.

DOI: 10.21883/FTP.2022.02.51967.9753

\section{1. Введение}

Квантовые точки (КТ) широко применяются в оптическом приборостроении, медицине и биологии. В последние годы внимание исследователей направлено на расширение их функциональности и оптимизацию свойств. Одно из направлений связано с синтезом сложных квантово-размерных структур [1-4]. Физические свойства таких структур предсказуемы, их регулируют, изменяя состав, размер и дефектность кристаллов. Для этого изменяют природу и последовательность слоев на сформированном ядре КТ, послойно легируют, контролируют размерную дисперсию $[5,6]$.

Для синтеза простых и многослойных квантовых точек, как и для объемных кристаллических люминофоров, широко применяются полупроводники группы A(II)B(VI) [7-12]. На первый план выдвигаются соединения кадмия и цинка, в частности разрабатываются КТ состава $\mathrm{Zn}_{x} \mathrm{Cd}_{1-x} \mathrm{~S}$ и их легированные структуры $[9,11]$. Квантовый выход фотолюминесценции КТ $\mathrm{Zn}_{x} \mathrm{Cd}_{1-x} \mathrm{~S}$ достигает 80\% [11]. Для формирования спектра люминесценции изменяют соотношения сульфидов кадмия и цинка, состав и концентрацию легирующих ионов.

Полосы люминесценции сульфидов цинка и кадмия находятся в видимой и ближней ИК областях спектра. Спектральные полосы ФЛ $\mathrm{CdS}$ расположены при длинах волн $>580$ нм. ФЛ $\mathrm{ZnS}$ в соответствии с большей шириной запрещенной зоны смещена в синюю область спектра. Люминесценция достаточно хорошо исследована, особенно для объемного вещества, и представлена в научной литературе [13-17]. Интенсивность ФЛ ZnS зависит от стехиометрического отношения $\mathrm{Zn}^{2+} / \mathrm{S}^{2-}[17]$. Ее максимум достигается при двойном избытке серы. Кроме того, количество ионов $\mathrm{S}^{2-}$ оказывает влияние на размер частиц сульфида и, соответственно, на положение спектральных полос. Для объяснения люминесценции $\mathrm{ZnS}$ привлекают схемы Шена-Классенса и Ламбе-Клика $[9,10]$. Люминесценция $\mathrm{CdS}$ связана с дефектами в объеме и, главным образом, на поверхности наноразмерных кристаллов. В первом случае она возникает при рекомбинации экситонов. Во втором - излучение связано с „краевыми“ уровнями зоны проводимости и валентной зоны, или уровнями, которые создают примесные центры в запрещенной зоне полупроводника. Основными дефектами кристаллов являются ионы серы в междоузлиях кристаллической решетки $\mathrm{CdS}$ и вакансии в подрешетке кадмия. Согласно $[18,19]$, для малых по размеру частиц $\mathrm{CdS}$ основным центром свечения является поверхностная вакансия серы $V_{\mathrm{S}}$, наличие которой приводит к формированию незаполненных $3 d$ орбиталей кадмия, играющих роль электронных ловушек [19] и формирующих донорные уровни энергии. Для описания ФЛ в этом случае привлекается донорно-акцепторный механизм Вильямса-Пренера $[9,10]$.

Эффективным способом формирования энергетической диаграммы КТ является их легирование, включая послойное внедрение различных катионов в кристаллическую структуру слоев. В качестве легирующих применяются ионы меди, марганца, серебра, хрома и другие [10,20-24]. В легированных полупроводниках, кроме рекомбинационной, наблюдается внутризонная люминесценция. Она связана с эмиссионными переходами электронов между собственными уровнями энергии активаторов. Значительное влияние на ФЛ оказывает характер распределения легирующих ионов в объеме и на поверхности частиц.

Востребованными оптическими активаторами являются ионы лантанидов. Они применяются в сочетании с 
неорганическими полупроводниками [25-31]. Исследованы преимущественно КТ, легированные ионами $\mathrm{Eu}^{3+}$ и $\mathrm{Tb}^{3+}$. В легированных структурах зарегистрирован сенсибилизационный перенос энергии из зоны проводимости и с уровней структурных дефектов частиц полупроводника на уровни энергии ионов $\mathrm{Ln}^{3+}$ [31]. Одним из условий переноса энергии является наложение полос ФЛ полупроводниковых частиц на полосы поглощения ионов лантанидов. Высокая оптическая прозрачность $\mathrm{ZnS}$ может позволить получить сенсибилизированную люминесценцию лантанидов на внутризонных переходах в структурах $\mathrm{ZnS}$ и $(\mathrm{Cd}, \mathrm{Zn}) \mathrm{S}$. Не менее важным является вопрос влияния ионов лантанидов на протекание рекомбинационных процессов. Это связано с реализацией обратного переноса энергии с уровней ионов $\mathrm{Ln}^{3+}$ на уровни дефектов полупроводника. В этой связи интерес представляют ионы $\mathrm{Nd}^{3+}$. Среди ионов лантанидов они характеризуются серией узких полос в видимой и ближней ИК области спектра с наибольшими коэффициентами поглощения. Введение ионов $\mathrm{Nd}^{3+}$ в полупроводниковую матрицу создает в ней активаторные центры, характеризующиеся системой уровней, наличие которых может существенно влиять на оптические свойства КТ, квантовых структур и композитов в целом.

Для получения КТ применяется коллоидный синтез [32-35]. Его проведение в органических средах минимизирует влияние молекул воды. Это имеет первостепенное значение для лантанидсодержащих систем. Колебательные обертоны $\mathrm{O}-\mathrm{H}$-связей являются причиной тушения люминесценции лантанидов или полного ее исчезновения. Однако в органических средах высока вероятность агрегирования КТ. Для стабилизации коллоидных растворов КТ применяются поверхностноактивные вещества [7], „зарядовый“ фактор [36], внедрение в полимерные матрицы. Для получения полимерных композитов предварительно синтезированные КТ помещают в раствор полимера и отверждают [37-39] или синтезируют непосредственно в процессе полимеризации мономера [40-42]. Во втором случае светопропускание акриловых композиций полимер/полупроводник при длинах волн $>450$ нм достигает $90-92 \%$ при толщине поглощающего слоя до 5 мм.

Учитывая значение и потенциальные возможности ионов неодима в создании новых оптических материалов, цель данной работы состояла в изучении влияния ионов $\mathrm{Nd}^{3+}$ на фотолюминесценцию квантовых точек сульфидов кадмия и цинка в полиакрилатной матрице, синтезированных при различной последовательности введения и концентрации исходных веществ в полимеризующуюся реакционную смесь.

\section{2. Характеристика объектов исследования и методики эксперимента}

Квантовые точки $(\mathrm{Cd}, \mathrm{Zn}, \mathrm{Nd}) \mathrm{S}$ синтезированы по методике $[42,43]$ разложением тиоацетамидных комплексов трифторацетатов цинка, кадмия и неодима в среде метилметакрилата (MМА) при нагревании до начала процесса полимеризации и далее при его полимеризации. На первой стадии синтеза при нагревании реакционных смесей $\left(t_{1}: 20\right.$ мин, $\left.70^{\circ} \mathrm{C}\right)$ образовывались коллоидные растворы КТ $[35,41]$. Об их образовании судили по возникновению опалесценции и изменению окраски с бесцветной до желто-зеленой (,канареечной“) в составax, содержащих CdS. Растворы, содержащие только $\mathrm{ZnS}$, оставались бесцветными. После образования коллоидных растворов в реакционные смеси вносили перекись бензоила $\left(\mathrm{Bz}_{2} \mathrm{O}_{2}\right)$ в количестве $0.10 \%$ от массы MMA и продолжали нагревать при температуре $70^{\circ} \mathrm{C}\left(t_{2}\right)$ до вязкого состояния. Вязкими растворами заполняли разборные стеклянные кюветы и продолжали полимеризацию в течение 24 ч до стеклообразного состояния композита. В результате синтезированы полимерные „стекла“ ПММА $/(\mathrm{Cd}, \mathrm{Zn}, \mathrm{Nd}) \mathrm{S}$ с различной структурной организацией частиц $(\mathrm{Cd}, \mathrm{Zn}, \mathrm{Nd}) \mathrm{S}$. Светопропускание композитов в области длин волн > 450 нм достигало $92 \%$ (5 мм). Окраска „стекол“ близка к окраске полимеризуемых растворов. Сиреневая окраска ионов неодима из-за невысоких коэффициентов поглощения и небольшой концентрации в составе композитов была заметна только в растворах и композитах на основе сульфида цинка.

Приготовление коллоидных растворов и далее полиакрилатных композитов можно описать следующими схемами:

ПММА/CdS и ПММА $/ \mathrm{ZnS}-\left[\mathrm{Cd}\left(\mathrm{CF}_{3} \mathrm{COO}\right)_{2} \cdot n \mathrm{H}_{2} \mathrm{O}\right.$ или $\mathrm{Zn}\left(\mathrm{CF}_{3} \mathrm{COO}\right)_{2} \cdot n \mathrm{H}_{2} \mathrm{O}+\mathrm{TAA}+\mathrm{MMA}+t_{1}\left(20\right.$ мин, $\left.70^{\circ} \mathrm{C}\right)$ $+\mathrm{Bz}_{2} \mathrm{O}_{2}+t_{2} \quad\left(24\right.$ ч, $\left.\left.\quad 70^{\circ} \mathrm{C}\right)\right] ; \quad \Pi M M A /(\mathrm{Cd}, \mathrm{Nd}) \mathrm{S} \quad$ и ПММА $/(\mathrm{Zn}, \mathrm{Nd}) \mathrm{S}-\left[\mathrm{Cd}\left(\mathrm{CF}_{3} \mathrm{COO}\right)_{2} \cdot n \mathrm{H}_{2} \mathrm{O}\right.$ или $\left(\mathrm{Zn}\left(\mathrm{CF}_{3} \mathrm{COO}\right)_{2} \cdot n \mathrm{H}_{2} \mathrm{O}+\mathrm{Nd}\left(\mathrm{CF}_{3} \mathrm{COO}\right)_{3} \cdot 3 \mathrm{H}_{2} \mathrm{O}+\mathrm{TAA}\right.$ $\left.\left.+\mathrm{MMA}+t_{1}\right)+\mathrm{Bz}_{2} \mathrm{O}_{2}+t_{2}\right] ; \Pi \mathrm{MMA} /(\mathrm{Cd}, \mathrm{Zn}) \mathrm{S}-$ $\left[\left(\mathrm{Cd}\left(\mathrm{CF}_{3} \mathrm{COO}\right)_{2} \cdot n \mathrm{H}_{2} \mathrm{O}+\mathrm{TAA}+\mathrm{MMA}+t_{1}\right)\right.$

$+\left(\mathrm{Zn}\left(\mathrm{CF}_{3} \mathrm{COO}\right)_{2} \cdot n \mathrm{H}_{2} \mathrm{O}+\mathrm{TAA}+\mathrm{MMA}\right)+t_{1}+\mathrm{Bz}_{2} \mathrm{O}_{2}+t_{2}$; $\Pi \mathrm{M} \mathrm{M} \mathrm{A} /(\mathrm{Cd}, \mathrm{Nd}) \mathrm{S} / \mathrm{ZnS}-\left[\left(\mathrm{Cd}\left(\mathrm{CF}_{3} \mathrm{COO}\right)_{2} \cdot n \mathrm{H}_{2} \mathrm{O}\right.\right.$ $\left.+\mathrm{Nd}\left(\mathrm{CF}_{3} \mathrm{COO}\right)_{3} \cdot 3 \mathrm{H}_{2} \mathrm{O}+\mathrm{TAA}+\mathrm{MMA}+t_{1}\right)$

$\left.+\left(\mathrm{Zn}\left(\mathrm{CF}_{3} \mathrm{COO}\right)_{2} \cdot n \mathrm{H}_{2} \mathrm{O}+\mathrm{TAA}+\mathrm{MMA}\right)+t_{1}+\mathrm{Bz}_{2} \mathrm{O}_{2}+t_{2}\right]$ ПMMA/CdS/ $(\mathrm{Zn}, \mathrm{Nd}) \mathrm{S}-\left[\left(\mathrm{Cd}\left(\mathrm{CF}_{3} \mathrm{COO}\right)_{2} \cdot n \mathrm{H}_{2} \mathrm{O}+\mathrm{TAA}\right.\right.$ $\left.+\mathrm{MMA}+t_{1}\right)+\left(\mathrm{Zn}\left(\mathrm{CF}_{3} \mathrm{COO}\right)_{2} \cdot n \mathrm{H}_{2} \mathrm{O}\right.$

$\left.\left.+\mathrm{Nd}\left(\mathrm{CF}_{3} \mathrm{COO}\right)_{3} \cdot 3 \mathrm{H}_{2} \mathrm{O}+\mathrm{TAA}+\mathrm{MMA}\right)+t_{1}+\mathrm{Bz}_{2} \mathrm{O}_{2}+t_{2}\right]$.

Концентрации трифторацетатов кадмия и цинка в конечных реакционных смесях (с учетом разведения при смешивании исходных растворов, если оно предусмотрено методикой) составляли: при получении $\mathrm{CdS}$ и $\mathrm{ZnS}$ по $1.0 \cdot 10^{-2}$ моль/л, при получении $(\mathrm{Cd}, \mathrm{Zn}) \mathrm{S}$ по $5.0 \cdot 10^{-3}$ моль/л. Концентрация трифторацетата неодима составляла: при получении $(\mathrm{Cd}, \mathrm{Nd}) \mathrm{S}$ и $(\mathrm{Zn}, \mathrm{Nd}) \mathrm{S}$ $1.0 \cdot 10^{-2}$ моль/л и $5.0 \cdot 10^{-3}$ моль/л (мольные соотношения $\mathrm{Cd}(\mathrm{Zn}): \mathrm{Nd}=1: 1 \quad$ и $2: 1)$, при получении $(\mathrm{Cd}, \mathrm{Nd}) \mathrm{S} / \mathrm{ZnS}$ и $\mathrm{CdS} /(\mathrm{Zn}, \mathrm{Nd}) \mathrm{S} 1.0 \cdot 10^{-3}$ моль/л (мольное соотношение $\mathrm{Cd}$ или $\mathrm{Zn}$ к $\mathrm{Nd}$ 5:1). Конечный объем растворов во всех случаях был равен 10 мл. Концентрация тиоацетамида в растворах была эквивалентна концентрации трифторацетатов цинка и кадмия, 
или их суммы. Введение ионов $\mathrm{Nd}^{3+}$ в концентрации, сопоставимой с концентрациями ионов $\mathrm{Cd}^{2+}$ и $\mathrm{Zn}^{2+}$, предполагало закрепление их части на поверхности частиц $\mathrm{CdS}, \mathrm{ZnS}$ и $(\mathrm{Cd}, \mathrm{Zn}) \mathrm{S}$, а также вхождение в полимерную матрицу в несвязанном с КТ состоянии.

Электронные спектры поглощения, фотолюминесценции и возбуждения фотолюминесценции композитов ПММА/ $(\mathrm{Cd}, \mathrm{Zn}, \mathrm{Nd}) \mathrm{S}$ зарегистрированы при комнатной температуре на спектрофлуориметре Shimadzu RF-5301PC.

\section{3. Результаты эксперимента и обсуждение}

Полиметилметакрилат (ПММА) является одним из наиболее прозрачных оптических полимеров. Его синтез, физические и химические свойства хорошо изучены и представлены в научной литературе [37]. Оптическая прозрачность ПММА при длинах волн > 400 нм достигает 93\% (5 мм), в тонких слоях она сопоставима со светопропусканием оптических неорганических стекол. ПММА люминесцирует в ближней УФ и в синей областях спектра. При инициировании полимеризации ММА перекисью бензоила $\left(\mathrm{Bz}_{2} \mathrm{O}_{2}\right)$ длинноволновая полоса люминесценции ПММА распространяется в область 450 нм. Она связана с продуктами разложения $\mathrm{Bz}_{2} \mathrm{O}_{2}$. Технология переработки ПММА позволяет изготавливать из него оптические изделия различной формы и размера. Одним из технологических недостатков ПММА является неудовлетворительная пленкообразующая способность в немодифицированном состоянии.

Полоса поглощения частиц $\mathrm{CdS}$ в композитах ПMМA/CdS находится в спектральном диапазоне $300-450$ нм. Сульфид цинка в ПММA/ZnS поглощает в диапазоне 280-360 нм. Максимумы полос расположены в области 360 и 310 нм соответственно. В коротковолновой части полосы перекрываются с полосами поглощения ПММА $[44,45]$. Расчет размера частиц $\mathrm{CdS}$ и $\mathrm{ZnS}$, проведенный по методике [34], показывает, что их диаметр в матрице ПММА не превышает 10 нм [35,41,42].

Композиты ПММА: $\mathrm{Nd}\left(\mathrm{CF}_{3} \mathrm{COO}\right)_{3}$ при увеличении концентрации соли $>0.10$ моль/(л полимеризуемой смеси) имеют интенсивную сиреневую окраску. В их оптическом спектре зарегистрирована серия узких полос поглощения ионов $\mathrm{Nd}^{3+}$ (рис. 1) [46]. Пиковая интенсивность полос линейно увеличивается вплоть до концентраций $\mathrm{Nd}\left(\mathrm{CF}_{3} \mathrm{COO}\right)_{3}$, близких к 1.0 моль/л, при сохранении базового светопропускания композитов. Уровни энергии, на которые переходят $4 f$-электроны из основного ${ }^{4} I_{9 / 2}$ электронного состояния ионов $\mathrm{Nd}^{3+}$, обозначены на рисунке (рис. 1). Большая часть из них расположена в запрещенной зоне сульфидов цинка и кадмия. Они создают в ней внутризонную энергетическую систему. ФЛ композитов ПММА: $\mathrm{Nd}\left(\mathrm{CF}_{3} \mathrm{COO}\right)_{3}$ проявляется двумя полосами с максимумами в области 890 и 1056 нм [46]. Базовая оптическая прозрачность

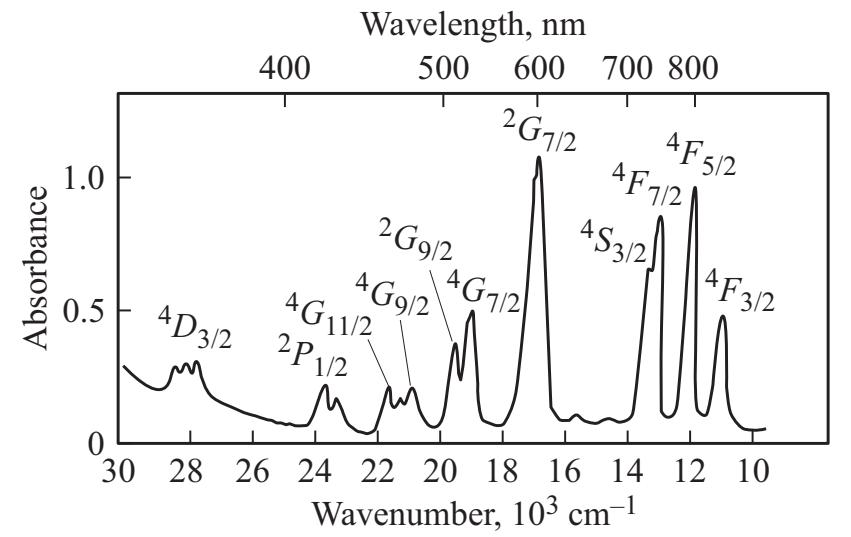

Рис. 1. Спектр поглощения ПММА: $\mathrm{Nd}\left(\mathrm{CF}_{3} \mathrm{COO}\right)_{3}$, $\mathrm{C}_{\mathrm{Nd}}=0.20$ моль/л $[46]$.

композитов при длинах волн > 400 нм достигает $92 \%$ при толщине образцов до 5 мм.

В спектрах фотолюминесценции композитов ПММA/CdS, зарегистрированных при длинах волн возбуждающего излучения 330 (рис. 2, $a$, спектр 1), 370 (рис. 2, $a$, спектр 2) и 440 нм (рис. 2, $a$, спектр 3) присутствует широкая сложная полоса ФЛ в области длин волн 430-780 нм. Ее максимумы соответствуют длинам волн 590 и 635 (640) нм (рис. 2,a). Полоса ФЛ в данной спектральной области связана с уровнями энергии структурных дефектов поверхностного слоя частиц CdS. В большей степени они возникают в результате искажения подрешетки серы. Красное смещение данной полосы в область длин волн > 600 нм происходит при увеличении концентрации дефектов на поверхности частиц [40-42]. В жидких средах также влияют сольватация и комплексообразование с компонентами среды на поверхности частиц. Увеличение интенсивности ФЛ при возбуждении излучением с длиной волны 370 нм объясняется благоприятным сочетанием энергии возбуждающего излучения с энергией уровней структурных дефектов. Малоинтенсивное плечо на восходящей ветви полосы ФЛ композита ПММА/CdS в области $450 \mathrm{Hм}$, проявляющееся при возбуждении излучением 330 нм (рис. 2, $a$, спектр 1]), вероятно, связано с люминесценцией полимерной матрицы.

После введения в реакционную смесь трифторацетата неодима в мольном соотношении $\mathrm{Cd}: \mathrm{Nd}=2: 1$ в спектрах ФЛ композитов ПММА/CdS: $\mathrm{Nd}^{3+}$ отмечается уширение полос, увеличение их интенсивности (рис. 2, $b$ и $c$ ), перераспределение интенсивности компонент полосы. Эти изменения связаны с внедрением ионов $\mathrm{Nd}^{3+}$ в поверхностный слой частиц $\mathrm{CdS}$. В результате в запрещенной зоне, кроме уровней энергии собственных дефектов $\mathrm{CdS}$, возникают уровни энергии дефектов, образованных ионами $\mathrm{Nd}^{3+}$, а также собственные уровни энергии ионов $\mathrm{Nd}^{3+}$. При этом отметим, что при таком усложнении энергетической диаграммы композита, в отличие от [47], люминесценция CdS не потушена.

Более существенные отличия в спектре ФЛ композита ПММА/CdS: $\mathrm{Nd}^{3+}$ произошли после увеличения 

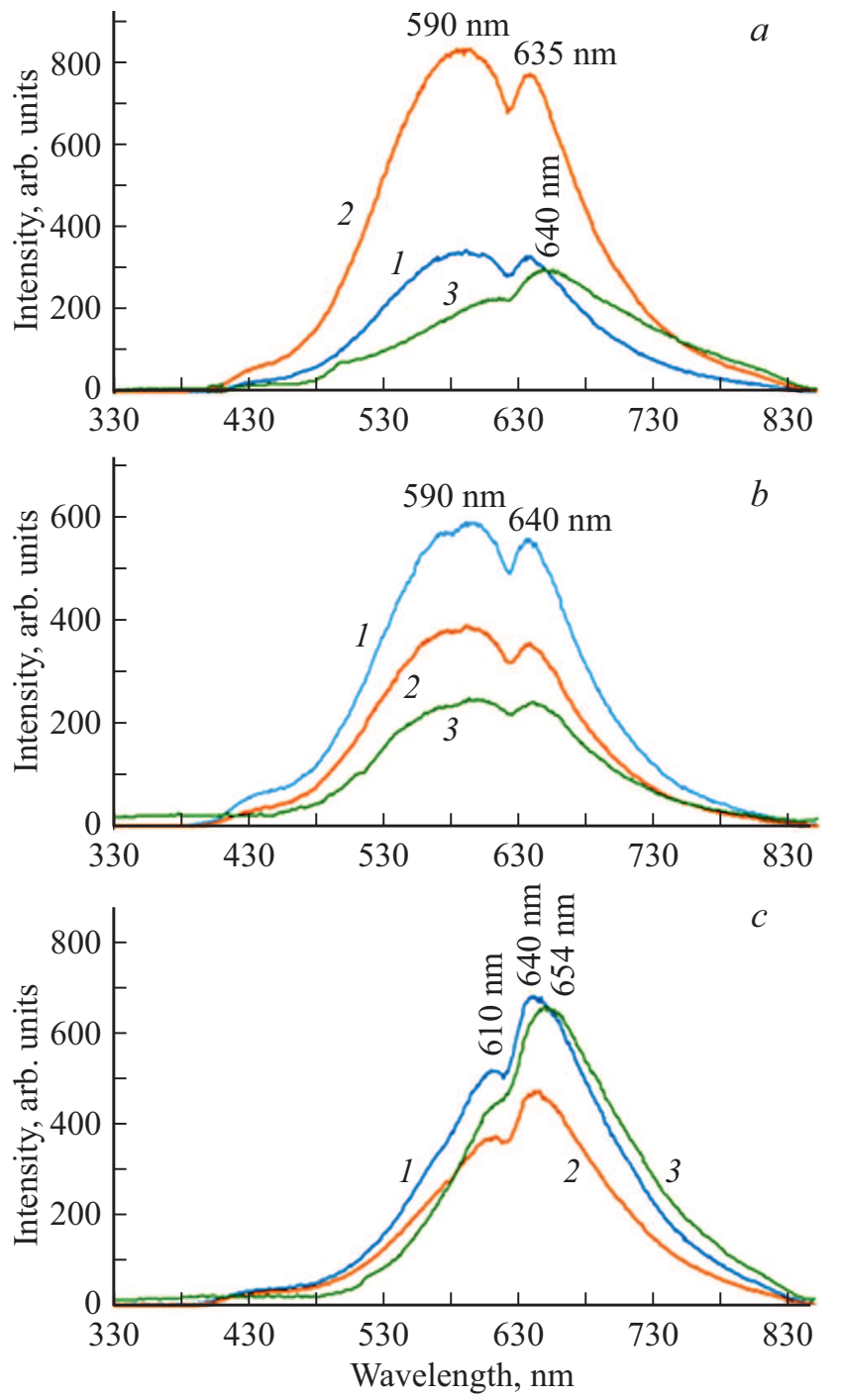

Рис. 2. Спектры фотолюминесценции композитов для длин волн возбуждающего излучения 330 (1), 370 (2) и 440 нм (3): a) ПММА/CdS, $\mathrm{C}_{\mathrm{Cd}}=1.0 \cdot 10^{-2}$ моль/л, b) ПММА/CdS: $\mathrm{Nd}^{3+}$, $\mathrm{C}_{\mathrm{Cd}}=1.0 \cdot 10^{-2}$ моль/л, $\quad \mathrm{C}_{\mathrm{Nd}}=5.0 \cdot 10^{-3}$ моль/л, c) ПММА/CdS: $\mathrm{Nd}^{3+}, \mathrm{C}_{\mathrm{Cd}}=\mathrm{C}_{\mathrm{Nd}}=1.0 \cdot 10^{-2}$ моль/л; ширина щелей монохроматора: $a) 5-5$ нм $(1-3), b$ и $c) 5-5$ нм $(1,3)$, 5-3 нм (2).

концентрации ионов $\mathrm{Nd}^{3+}$ до мольных соотношений $\mathrm{Cd}: \mathrm{Nd}=1: 1$ (рис. 2,c). Полоса ФЛ оказалась батохромно смещена, особенно при возбуждении излучением с длиной волны 440 нм. Максимумы ее компонент сдвинулись до 610 и 654 нм. Интенсивность длинноволновой компоненты полосы увеличилась. Данные изменения связаны с увеличением концентрации дефектов, образованных ионами $\mathrm{Nd}^{3+}$, на поверхности частиц. При возбуждении излучением с длиной волны 440 нм увеличилась вероятность участия в актах преобразования энергии источника в ФЛ собственных уровней энергии ионов $\mathrm{Nd}^{3+}$, основная часть которых расположена в спектре поглощения при длинах волн меньше 440 нм (рис. 1). Кроме того, комплексообразование ионов $\mathrm{Nd}^{3+}$, лигандами в котором являются трифторацетат-ионы и макромолекулы посредством кислорода карбонильных групп, химически связывает полупроводниковые частицы, расположенные в пустотах надмолекулярной структуры полимера, с матрицей. Учитывая относительно высокую концентрацию ионов $\mathrm{Nd}^{3+}$ (мольное соотношение $\mathrm{Cd}: \mathrm{Nd}=1: 1)$, часть их находится в полимерной матрице в несвязанном с частицами $\mathrm{CdS}$ состоянии. Также отметим, что увеличение концентрации ионов $\mathrm{Nd}^{3+}$ не привело к тушению люминесценции $\mathrm{CdS}$. Это может косвенно указывать на существование обратного переноса энергии с уровней ионов $\mathrm{Nd}^{3+}$ на ниже расположенные уровни структурных дефектов с последующей рекомбинацией зарядов или безызлучательной релаксацией.

В спектрах фотолюминесценции композитов ПММА/ZnS и ПММА/ZnS: $\mathrm{Nd}^{3+}$ зарегистрирована сложная полоса в интервале длин волн 380-560 нм (рис. 3). При увеличении длины волны возбуждающего излучения максимум полосы ФЛ смещается в длинноволновую часть спектра $(430 \mathrm{Hм} \rightarrow 445 \mathrm{Hм})$. После введения в реакционную смесь трифторацетата неодима пиковая интенсивность полосы ФЛ композита ПMМA/ZnS: $\mathrm{Nd}^{3+}$ увеличилась. Это произошло главным образом в результате увеличения интенсивности ее длинноволновой компоненты. Увеличение интенсивности полосы нами связано с возросшей дефектностью частиц в результате включения в их структуру ионов $\mathrm{Nd}^{3+}$. После увеличения их концентрации до мольного соотношения $\mathrm{Zn}: \mathrm{Nd}=1: 1$ полуширина полосы ФЛ увеличилась. Как и в случае $\mathrm{CdS}$, это объясняется усилением роли структурной неоднородности поверхности частиц. Уменьшение интенсивности полосы (рис. 3,c) объясняем меньшим участием собственных уровней энергии ионов $\mathrm{Nd}^{3+}$ в переносе энергии между системами сульфида цинка и ионов $\mathrm{Nd}^{3+}$. Меньшую зависимость полосы ФЛ композитов ПММА/ZnS от влияния ионов $\mathrm{Nd}^{3+}$, в отличие от их влияния в композитах ПММА/CdS, связываем с большей шириной запрещенной зоны $\mathrm{ZnS}$ и, соответственно, изменившимся сочетанием энергий уровней структурных дефектов и собственных уровней энергии ионов $\mathrm{Nd}^{3+}$.

B спектре фотолюминесценции композита ПММА/(Cd,Zn)S (рис. 4) зарегистрирована сложная полоса, включающая компоненты, связанные с ФЛ $\mathrm{CdS}$, максимум расположен в области 590-653 нм, и $\mathrm{ZnS}$ с максимумом в области 450 нм. Полученные результаты соответствуют данным, приведенным в работе [41]. Характер происходящих изменений при изменении длины волны возбуждающего излучения сопоставим с изменениями в спектре композиции ПMMA/CdS. Это объясняется большей зависимостью спектра ФЛ $\mathrm{CdS}$ от длины волны возбуждающего излучения (рис. 2 и 3, спектры 3). Взаимное влияние сульфидов кадмия и цинка проявляется выравниванием пиковых интенсивностей полос, зарегистрированных при возбуждении излучением с длинами волн 370 и 440 нм, а также большим изменением контура полосы 

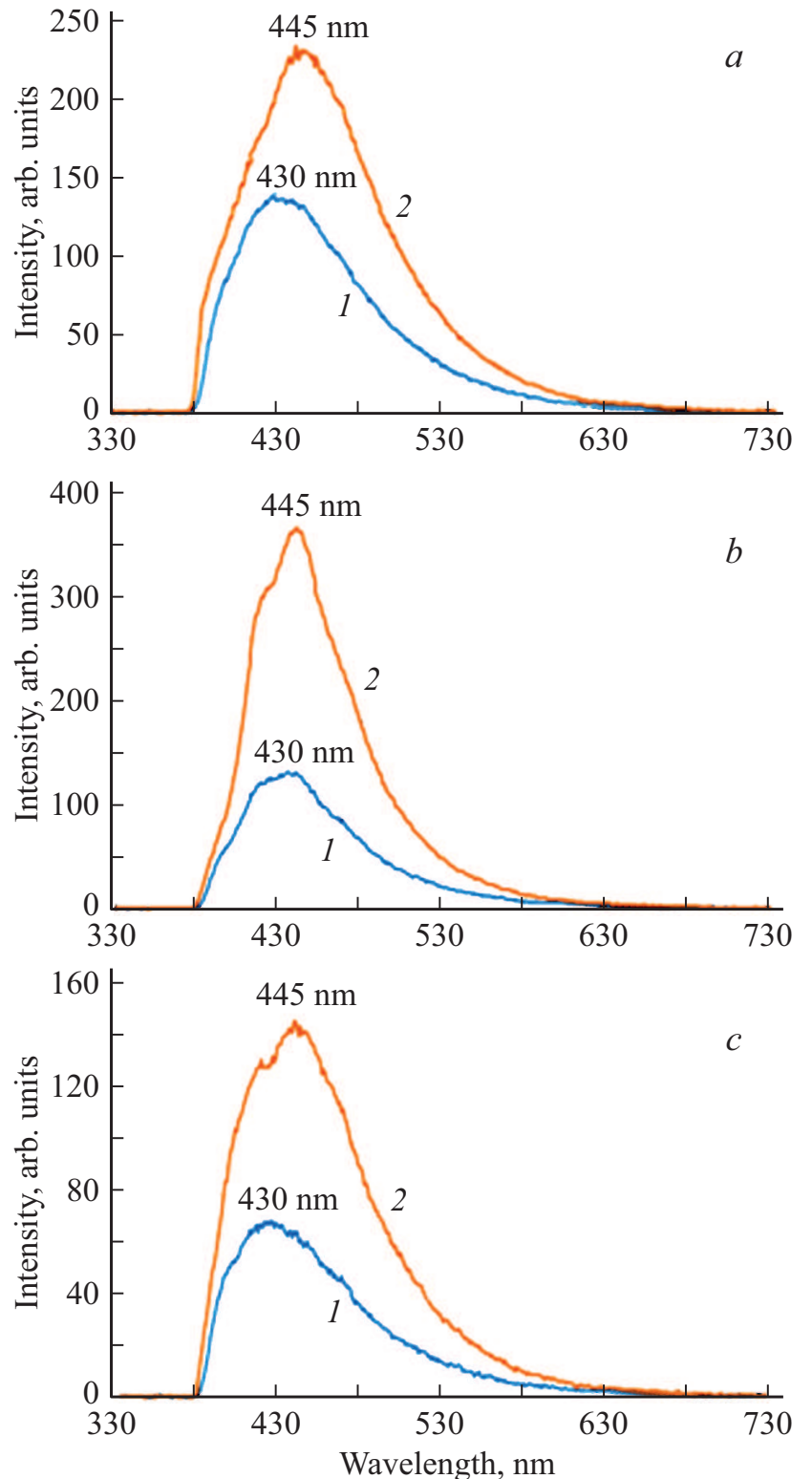

Рис. 3. Спектры фотолюминесценции композитов для длин волн возбуждающего излучения 330 (1), $370 \mathrm{Hм} \mathrm{(2):}$ a) ПММА/ZnS, $\mathrm{C}_{\mathrm{Zn}}=1.0 \cdot 10^{-2}$ моль/л, b) ПММА/ZnS: $\mathrm{Nd}^{3+}$, $\mathrm{C}_{\mathrm{Zn}}=1.0 \cdot 10^{-2}$ моль/л, $\quad \mathrm{C}_{\mathrm{Nd}}=5.0 \cdot 10^{-3}$ моль/л, c) ПММА/ZnS: $\mathrm{Nd}^{3+}, \mathrm{C}_{\mathrm{Zn}}=\mathrm{C}_{\mathrm{Nd}}=1.0 \cdot 10^{-2}$ моль/л; ширина щелей монохроматора 5-5 нм.

при возбуждении излучением с длиной волны 440 нм, как в спектрах композиций ПММА/CdS.

После введения в реакционную смесь трифторацетата неодима одновременно с трифторацетатом кадмия в спектрах ФЛ композиции ПММА $/(\mathrm{Cd}, \mathrm{Nd}) \mathrm{S} / \mathrm{ZnS}$ (рис. $4, b$ ) зарегистрировано увеличение относительной интенсивности длинноволновой компоненты полосы и смещение ее максимума до 653 нм $\left(\lambda_{\mathrm{exc}}=440\right.$ нм$)$. Также отмечается значительное ее уширение по ниспадающей ветви. Наблюдающиеся изменения связаны с внедрением в поверхность $\mathrm{CdS}$ ионов $\mathrm{Nd}^{3+}$ с образованием разделя- ющего слоя между $\mathrm{CdS}$ и $\mathrm{ZnS}$, образованного сульфидом кадмия с большей концентрацией ионов $\mathrm{Nd}^{3+}$. При введении трифторацетата неодима в реакционную смесь одновременно с трифторацетатом цинка наблюдается тушение люминесценции $\mathrm{CdS}$ (рис. 4, c). Это происходит в результате внедрения ионов $\mathrm{Nd}^{3+}$ в поверхностный слой $\mathrm{ZnS}$ с формированием на поверхности частиц $\mathrm{CdS} / \mathrm{ZnS}$ слоя комплексных соединений, ограничивающих проникновение возбуждающего излучения к внутреннему слою CdS.

В спектрах возбуждения ФЛ композитов, содержащих нелегированные частицы $\mathrm{CdS}$ (рис. 5, $a$, спектр 1), $\mathrm{ZnS}$ (рис. 5, $a$, спектр 2) и $(\mathrm{Cd}, \mathrm{Zn}) \mathrm{S}$ (рис. 5, $a$, спектр 3), наблюдаются соответствующие КТ полосы в интервале
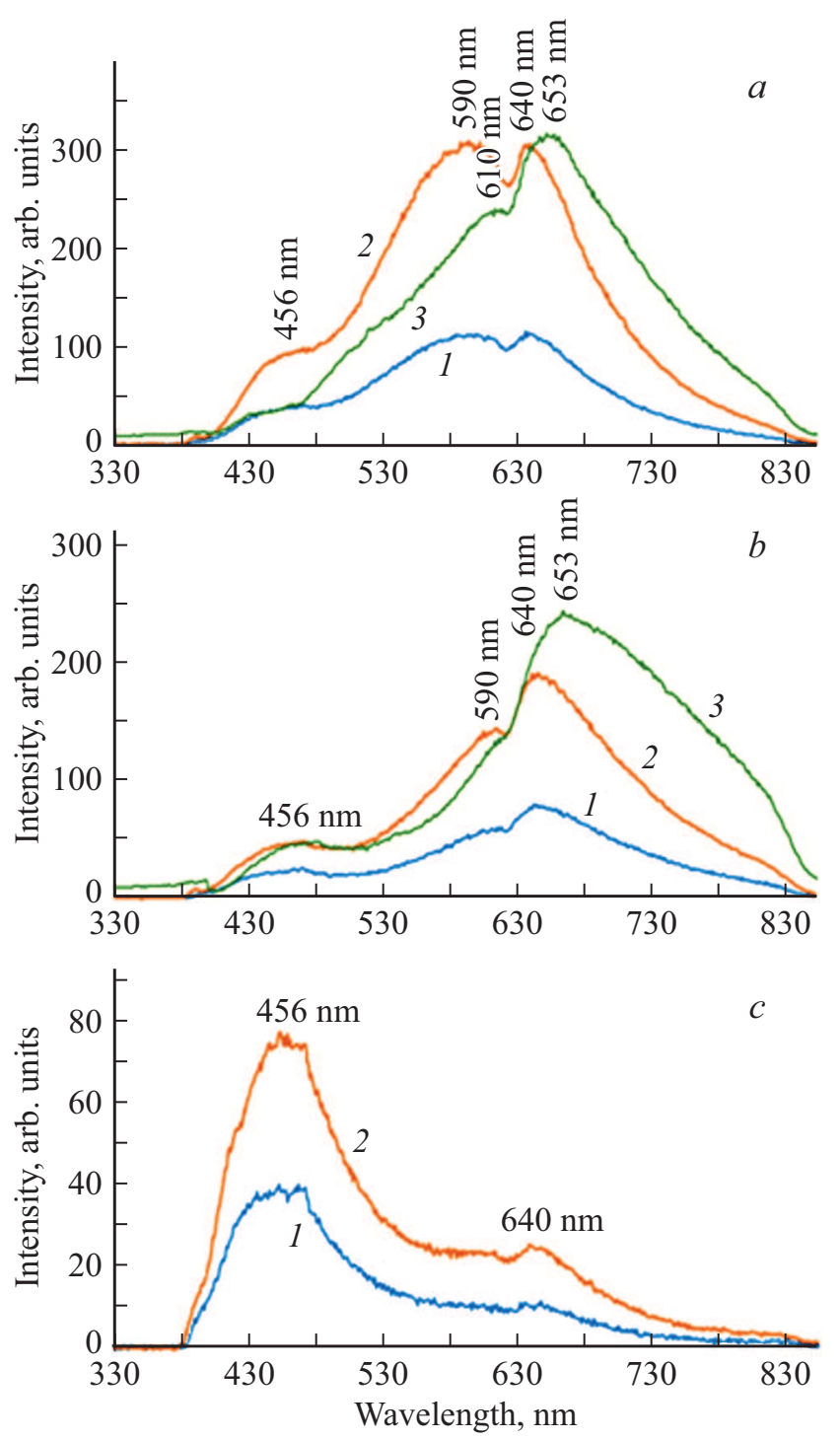

Pис. 4. Спектры фотолюминесценции композитов для длин волн возбуждающего излучения 330 (1), 370 (2), 440 нм (3): a) ПММА/(Cd, Zn $) \mathrm{S}, \mathrm{C}_{\mathrm{Cd}}=\mathrm{C}_{\mathrm{Zn}}=5.0 \cdot 10^{-3}$ моль/л, b) ПММА $/(\mathrm{Cd}, \mathrm{Nd}) \mathrm{S} / \mathrm{ZnS}, \quad \mathrm{C}_{\mathrm{Cd}}=\mathrm{C}_{\mathrm{Zn}}=5.0 \cdot 10^{-3}$ моль/л, $\mathrm{C}_{\mathrm{Nd}}=1.0 \cdot 10^{-3}$ моль/л, $\quad$ c) ПММА/CdS/(Zn, Nd)S, $\mathrm{C}_{\mathrm{Cd}}=\mathrm{C}_{\mathrm{Zn}}=5.0 \cdot 10^{-3}$ моль/л, $\mathrm{C}_{\mathrm{Nd}}=1.0 \cdot 10^{-3}$ моль/л; ширина щелей монохроматора 5-5 нм. 

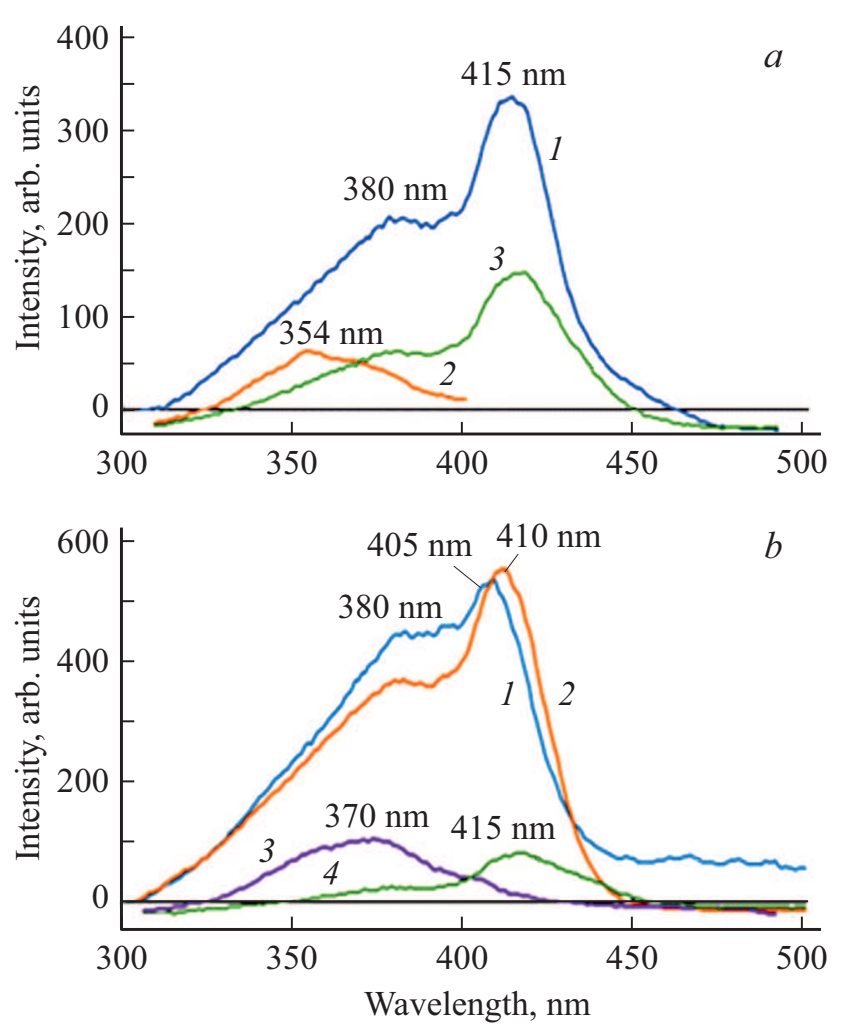

Рис. 5. Спектры возбуждения ФЛ ( $\left.\left.\lambda_{\mathrm{L}}, \mathrm{HM}\right): a\right)$ спектр 1 ПММА/CdS (638), спектр 2 - ПММА/ZnS (446), спектр 3 ПММА/(Cd,Zn)S (592); b) спектр 1 - ПММА/(Cd, Nd)S, $\mathrm{Cd}: \mathrm{Nd}=1: 1, \quad$ (610), спектр $2-$ ПMМA/(Cd, Nd)S, $\mathrm{Cd}: \mathrm{Nd}=2: 1 \quad$ (615), спектр $3-$ ПMМA/(Zn, Nd)S, $\mathrm{Zn}: \mathrm{Nd}=2: 1$, (440), спектр $4-$ ПММА/(Cd, Nd)S/ZnS (645).

длин волн 310-450 нм. Максимумы полос возбуждения батохромно смещены относительно максимумов, соответствующих им полос в спектрах поглощения [44,45]. Это подтверждает определяющую роль уровней структурных дефектов при получении композитами энергии источника. Сложность полос объясняется неэквивалентностью люминесцирующих центров в объеме и на поверхности полупроводниковых частиц. Например, полоса возбуждения ФЛ композитов ПММА/CdS имеет два выраженных максимума в области 380 и 415 нм (рис. 5, a, спектр 1). Она накладывается на ниспадающую ветвь полосы поглощения частиц $\mathrm{CdS}$ в композите ПMМА/CdS, максимум которой расположен в области 360 нм. Это позволяет говорить о том, что возбуждение ФЛ композитов связано с переходами электронов из валентной зоны на краевые уровни зоны проводимости и на уровни структурных дефектов частиц $\mathrm{CdS}$. Полученные результаты соответствуют данным [42,44,45]. Полоса в спектре возбуждения композита ПММА/ $(\mathrm{Cd}, \mathrm{Zn}) \mathrm{S}$ (рис. 5, $a$, спектр 3) определяется энергетической системой $\mathrm{CdS}$. Это связано с его меньшей шириной запрещенной зоны и, соответственно, положением зон на энергетической диаграмме композита ПММА/ $(\mathrm{Cd}, \mathrm{Zn}) \mathrm{S}$.

$\mathrm{B}$ спектрах возбуждения ФЛ композитов, содержащих легированные частицы, полосы уширены, изменена их структура (рис. $3, b$ ). Введение в композиты ионов $\mathrm{Nd}^{3+}$ привело к батохромному смещению полосы и ее длинноволнового максимума при увеличении соотношения $\mathrm{Cd}: \mathrm{Nd}$ (рис. 5, $b$, спектры 1 и 2). Такой же эффект, только несколько скрытый уширением полос, наблюдается в композитах ПММА/ $(\mathrm{Cd}, \mathrm{Zn}, \mathrm{Nd}) \mathrm{S}$. Спектральные изменения объясняются усложнением энергетической диаграммы композитов в результате введения ионов $\mathrm{Nd}^{3+}$, создающих дополнительные дефекты в кристаллических структурах $\mathrm{CdS}$ и $\mathrm{ZnS}$, а также дополняющих диаграмму набором собственных уровней энергии, расположенных в запрещенной зоне полупроводниковой системы. Кроме того, спектральные изменения объясняются ограничением доступа энергии к внутреннему слою $\mathrm{CdS}$ после легирования внешнего слоя $\mathrm{ZnS}$.

\section{4. Заключение}

Методом коллоидного синтеза в среде метилметакрилата синтезированы КТ на основе сульфидов кадмия и цинка, легированных ионами $\mathrm{Nd}^{3+}$. Термической полимеризацией ММА в блоке коллоидные растворы переведены в стеклообразное состояние. Синтезированы композиты ПММА/ $(\mathrm{Cd}, \mathrm{Zn}, \mathrm{Nd}) \mathrm{S}$, отличающиеся структурной организацией частиц. Показано, что после легирования $\mathrm{CdS}, \mathrm{ZnS}$ и $\mathrm{CdS} / \mathrm{ZnS}$ ионами $\mathrm{Nd}^{3+}$ рекомбинационная ФЛ полупроводниковых частиц сохраняется. Легирование внешнего слоя $\mathrm{ZnS}$ приводит к затуханию ФЛ внутреннего $\mathrm{CdS}$ в результате образования энергетических уровней, связанных с дефектами на поверхности внешнего слоя $\mathrm{ZnS}$ и комплексообразования ионов $\mathrm{Nd}^{3+}$ c компонентами матрицы, усложняющих энергетическую диаграмму композита, увеличивающих вероятность обмена энергией между полупроводниковой системой и собственными уровнями энергии ионов $\mathrm{Nd}^{3+}$.

\section{Конфликт интересов}

Авторы заявляют, что у них нет конфликта интересов.

\section{Список литературы}

[1] H.P. Feng, L. Tang, G.M. Zeng, X. Ren, B. Song, C. Liang, M.Y. Wei, J.F. Yu, Y. Zhou, Y.C. Deng. Adv. Colloid Interface, 267, 26 (2019).

[2] T.A. Esquivel-Castro, M.C. Ibarra-Alonso, J. Oliva, A. Martínez-Luévanos. Mater. Sci. Eng. C, 96, 915 (2019).

[3] X. Tong, X.-T. Kong, C. Wang, Y. Zhou, F. Navarro-Pardo, D. Barba, D. Ma, S. Sun, A.O. Govorov, H. Zhao, Z.M. Wang, F. Rosei. Adv. Sci., 5 (8), 1800656 (2018).

[4] G.S. Selopal, H. Zhao, G. Liu, H. Zhang, X. Tong, K. Wang, J. Tang, X. Sun, S. Sun, F. Vidal, Y. Wang, Z.M. Wang, F. Rosei. Nano Energy, 55, 377 (2019).

[5] C. Rosiles-Perez, Cerdán-Pasarán, Sidhik S., D. Esparza, T. Lopez-Luke, E. de la Rosa. Solar Energy, 174, 240 (2018).

[6] P. Kunstman, J. Coulon, O. Kolmykov, H. Moussa, L. Balan, Gh. Medjahdi, J. Lulek, R. Schneider. J. Luminesc., 194, 760 (2018). 
[7] R.N. Bhargava, D. Gallagher, X. Hong, A. Nurmikko. Phys. Rev. Lett., 72, 416 (1994).

[8] М.Ф. Буланый, А.В. Коваленко, Б.А. Полежаев, Т.А. Прокофьев. ФТП, 43 (6), 745 (2009).

[9] T.V. Vineeshkumar, R.D. Rithesh, S. Prasanth, N.V. Unnikrishnan, R. Philip, C. Sudarsanakumar. Optical Mater., 37, 439 (2014).

[10] J.K. Saluja, Y. Parganiha, N. Tiwari, V. Dubey, R. Tiwari, A. Prabhath. Optik, 127, 7958 (2016).

[11] T.V. Vineeshkumar, D. Rithesh Raj, S. Prasanth, Pranitha Sankar, N.V. Unnikrishnan, V.P. Mahadevan Pillai, C. Sudarsanakumar. Optical Mater., 58, 128 (2016).

[12] S. Rudra, G.H. Debnath, P. Mukherjee. RSC Adv., 8, 18093 (2018).

[13] О.Н. Казанкин, Л.Я. Марковский, И.А. Миронов, Ф.М. Пекерман, Л.Н. Петошина. Неорганические люминофоры (Л., Химия, 1975).

[14] И.А. Акимов, И.Ю. Денисюк, А.М. Мешков. Опт. и спектр., 72 (4), 1026 (1992).

[15] I. Zgaren, K. Sellami, S. Jaziri. Sensor Lett., 7 (5), 967 (2009).

[16] В.Н. Серова. Вестн. Казанского технол. ун-та, 9, 221 (2010).

[17] В.Г. Корсаков, М.М. Сычев, В.В. Бахметьев. Конденсированные среды и межфазные границы, 14 (1), 41 (2012).

[18] Н.К. Морозова, Н.Д. Данилевич, В.И. Олешко, С.С. Вильчинская. Изв. вузов. Электроника, 95 (3), 3 (2012).

[19] А.С. Перепелица. Дис. канд. хим. наук (Воронеж, Воронеж. гос. ун-т, 2017).

[20] Т.А. Кучакова, Г.В. Весна, В.А. Макара. ФТП, 38 (11), 1316 (2004).

[21] Ю.Ю. Бачериков, И.П. Ворона, С.В. Оптасюк, В.Е. Родионов, А.А. Стадник. ФТП, 38 (9), 1025 (2004).

[22] М.Ф. Буланый, А.В. Коваленко, Б.А. Полежаев, Т.А. Прокофьев. ФТП, 43 (6), 745 (2009).

[23] W. Zhu, C. Wang, X. Li, M.S. Khan, X. Sun, H. Ma. Biosens. Bioelectron., 97, 115 (2017).

[24] C.A. Rodríguez, A.C. Mera, L. Pizarro-Castillo, M. Ashfaq, M.G. Sandoval-Paz, M.J.C. Burgos, P. Manidurai, S. Suárez. Mater. Sci. Semicond. Process., 131, 105839 (2021).

[25] C.A. Tuan, V.H. Yen, V.H. Yen, K.C. Cuong, N.T.M. Thuy, P.M. An, N.T.B. Ngoc, D.T. Hue, A. Xayyadeth, Y. Peng, N.N. Le, N.T.K. Van, L.T. Ha, N.T. Kien, C.V. Ha. J. Luminesc., 236, 118106 (2021)

[26] P. Mukherjee, Ch.M. Shade, A.M. Yingling, D.N. Lamont, D. Waldeck, S. Petoud. J. Phys. Chem. A, 115 (16), 4031 (2011).

[27] P. Mukherjee, R.F. Sloan, Ch.M. Shade, D.H. Waldeck, S. Petoud. J. Phys. Chem. C, 117 (27), 14451 (2013).

[28] Z. Liang, J. Mu, L. Han, H. Yu. J. Nanomaterials, Article ID 519303 (2015).

[29] M. Bhar, S. Rudra, P. Mukherjee. J. Phys. Chem. C, 124 (12), 6588 (2020).

[30] G.H. Debnath, P. Mukherjee, D.H. Waldeck. J. Phys. Chem. C, 124, 26495 (2020).

[31] Д.О. Сагдеев. Автореф. канд. дис. (Казань, КНИИТУ, 2019).

[32] Т.Н. Щерба. Автореф. канд. дис. (М., МГУ, 2011).

[33] E. Ramya, M.V. Rao, D.N. Rao. Physica E, 107, 24 (2019).

[34] Р.Ф. Хайрутдинов. Успехи химии, 67 (2), 125 (1998).

[35] В.П. Смагин, Д.А. Давыдов, Н.М. Унжакова, А.А. Бирюков. Журн. неорган. химии, 60 (12), 1734 (2015).
[36] А.А. Бирюков, Т.И. Изаак, В.А. Светличный, О.В. Бабкина. Изв. вузов. Физика, 49 (12), 81 (2006).

[37] В.Н. Серова. Оптические и другие материалы на основе прозрачных полимеров (Казань, КГТУ, 2010).

[38] S. Mohan, O.S. Oluwafemi, S.P. Songca, S.C. George, P. Miska, D. Rouxel, N. Kalarikkal, S. Thomas. Mater. Sci. Semicond. Process., 39, 587 (2015).

[39] R.M. Abozaid, Z.Ž. Lazarević, I. Radović, M. Gilić, D. Šević, M.S. Rabasović, I. Radović. Optics Mater., 92, 405 (2019).

[40] А.А. Бирюков. Дис. канд. хим. наук (Томск, ТГУ, 2005).

[41] В.П. Смагин, Н.С. Еремина, А.А. Исаева. Журн. неорган. химии, 62 (1), 130 (2017).

[42] А.А. Исаева, В.П. Смагин. ФТП, 54 (5), 435 (2020).

[43] А.А. Исаева, В.П. Смагин. Журн. неорган. химии, 64 (10), 1020 (2019).

[44] В.П. Смагин, А.А. Исаева. Письма ЖТФ, 47 (16), 46 (2021).

[45] В.П. Смагин, А.А. Исаева. ЖТФ, 91 (5), 808 (2021).

[46] В.П. Смагин, Г.М. Мокроусов. Физико-химические аспекты формирования и свойства оптически прозрачных металлсодержсащих полимерных материалов (Барнаул, АлтГУ, 2014). http://elibrary.asu.ru/xmlui/bitstream/ handle/asu/840/read.7book? sequence $=1$

[47] А.А. Исаева, В.П. Смагин. Изв. вузов. Химия и хим. технология, 63 (11) 82 (2020).

Редактор Г.А. Оганесян

\section{Effect of neodymium (III) ions of the photoluminescence of cadmium and zinc sulfides in a polyacryate matrix}

\author{
V.P. Smagin, A.A. Isaeva, E.A. Shelepova
}

Altai State University, 656049 Barnaul, Russia

Abstract Nanoscale particles $\mathrm{CdS}: \mathrm{Nd}^{3+}, \quad \mathrm{ZnS}: \mathrm{Nd}^{3+}$ and $(\mathrm{Cd}, \mathrm{Zn}) \mathrm{S}: \mathrm{Nd}^{3+}$ were synthesized and doped in a polymerizing methyl methacrylate medium during the production of optically transparent polyacrylate composites of the composition PMMA/CdS: $\mathrm{Nd}^{3+}, \mathrm{PMMA} / \mathrm{ZnS}: \mathrm{Nd}^{3+}$ and PMMA/(Cd,Zn $) \mathrm{S}: \mathrm{Nd}^{3+}$. The excitation of photoluminescence and photoluminescence of semiconductor structures in a polyacrylate matrix is associated with the transition of electrons from the valence band to the conduction band and to the levels of structural defects of particles, followed by recombination at these levels. Based on changes in the excitation spectra of photoluminescence and photoluminescence composites, assumptions are made about the structure of particles, the distribution of $\mathrm{Nd}^{3+}$ ions in it and their effect on photoluminescence. 